\title{
Affective-prosodic deficits in schizophrenia: profiles of patients with brain damage and comparison with relation to schizophrenic symptoms
}

\author{
E D Ross, D M Orbelo, J Cartwright, S Hansel, M Burgard, J A Testa, R Buck
}

\begin{abstract}
Objective-Although affective prosody seems to be a dominant and lateralised communication function of the right hemisphere, focal lesions of either hemisphere may cause problems with its modulation. When impairment occurs after brain damage, the profiles of affective-prosodic disturbances differ depending on the hemisphere injured. $\mathrm{Pa}$ tients with left brain damage (LBD) improve their performance whereas patients with right brain damage (RBD) do not when the verbal-articulatory demands of the test stimuli are reduced systematically. One of the major arguments for a right hemispheric contribution to schizophrenia has been the documentation of affective prosodic deficits under the assumption that these abnormalities reflect right hemispheric dysfunction. Thus, an essential question to resolve is whether the profile of affective prosodic disturbances in schizophrenia is similar to LBD or
\end{abstract} RBD, or represents a unique variation.

Department of Neurology, University of Oklahoma Health Sciences Center, and the VA Medical Center, (11AZ), $921 \mathrm{NE}$ 13th Street; Oklahoma City, OK 73104, USA

E D Ross

D M Orbelo

J A Testa

Clinical Research

Program,

Neuropsychiatric

Research Institute,

Fargo, ND, USA

E D Ross

$S$ Hansel

M Burgard

Department of Communication Sciences, University of Connecticut, Storrs, CT, USA

J Cartwright

R Buck

Correspondence to: Dr E D Ross

elliot-ross@ouhsc.edu

Received 18 April 2000 and in revised form

2 November 2000

Accepted 8 December 2000
Methods-Data were collected from four subject groups: 45 chronic, medicationstabilised, schizophrenic patients, 10 patients with focal LBD, nine patients with focal RBD, and 19 controls. All groups were tested on the aprosodia battery, which uses stimuli having incrementally reduced verbal-articulatory demands. Schizophrenic and aphasic symptoms were evaluated using standard assessment tools.

Results-For patients with impaired performance on the aprosodia battery, schizophrenic patients were statistically identical to patients with RBD and robustly different from those with LBD. Thirty eight schizophrenic patients $(84.4 \%)$ were found to have some type of affective prosodic deficit with the predominant pattern indicating, at minimum, right posterior sylvian dysfunction $(57.8 \%)$. When schizophrenic symptoms and aprosodic deficits were examined using a principal component analysis, affective comprehension and repetition loaded uniquely as separate factors.

Conclusions-The profile of affectiveprosodic deficits found in impaired schizophrenic patients is characteristic of
RBD, supporting the concept that schizophrenia is a bihemispheric disease process. These deficits may also represent cardinal symptoms of schizophrenia as they are highly prevalent and, except for spontaneous affective prosody, are not associated statistically with traditional clusters of schizophrenic symptoms. (F Neurol Neurosurg Psychiatry 2001;70:597-604)

Keywords: schizophrenia; affective prosody; aphasia

One of the cardinal negative symptoms of schizophrenia is flattening of affective demeanor, ${ }^{12}$ a phenomenon that is also seen after focal injury to the right hemisphere. ${ }^{3-6}$ The behavioural flattening after right brain damage (RBD) is characterised by loss of the ability to insert gestural and affective-prosodic features into speech and communication while leaving linguistic-propositional features intact. Depending on lesion location, focal damage to the right hemisphere may impair comprehension, repetition, and spontaneous production of affective prosody and gestures in various combinations that are analogous to aphasic deficits after focal lesions of the left hemisphere. ${ }^{4} 6$ These syndromes are called "aprosodias" and suggest that the right hemisphere has a dominant role in modulating affective prosody. ${ }^{467}$ Loss of the experiential aspects of emotion (emotional blunting) does not accompany the loss of spontaneous affective behaviours in patients with aprosodias. ${ }^{4689}$ Emotional blunting, however, has been considered a hallmark of schizophrenia although recent studies have shown that this may not be correct. ${ }^{10-12}$

Some studies to date have documented disturbances of affective prosody in schizophrenic patients. ${ }^{13-21}$ Disturbances in the production of affective prosody have been correlated with the presence of negative behaviour al symptoms and likened to deficits found after RBD. ${ }^{1516181921}$ By contrast, basic verballinguistic features of language associated with the left hemisphere are usually preserved in schizophrenic patients. ${ }^{19}{ }^{21}$ Overt aphasic syndromes are rarely encountered but minor abnormalities of propositional language may occur that are usually attributable to either the patients' underlying thought disorder, loss of executive control, or a right hemispheric disturbance. ${ }^{22-25}$ Because of the above findings and related neuropsychological deficits that 
point to significant right hemispheric impairment in schizophrenia, some investigators have called into question the widely accepted hypothesis that schizophrenia is predominantly a disorder of the left hemisphere. ${ }^{16-19} 2627$

CALLOSAL FUNCTION IN SCHIZOPHRENIA

Over the past decade, research has suggested that loss or possible enhancement of interhemispheric integration may contribute to schizophrenic symptoms. ${ }^{28}$ Although findings have been variable, including negative results, ${ }^{29} 30$ taken as a whole there seems to be sufficient data to support the idea that some groups of schizophrenic patients show abnormalities of callosal integration of behavioural functions. ${ }^{28}$ When present, thinning of the callosum has been associated with late onset, positive symptom schizophrenia that is accompanied by loss of the interhemispheric transfer of information whereas thickening of the callosum has been associated with early onset, negative symptom schizophrenia that is accompanied by possible increases in interhemispheric transfer of information. ${ }^{28}$

LATERALISATION OF AFFECTIVE PROSODY AND CALLOSAL INTEGRATION OF LANGUAGE FUNCTIONS

Although affective prosody has been posited to be a dominant and lateralised function of the right hemisphere, some publications have reported considerable disturbances in the modulation of affective prosody after left brain damage (LBD) suggesting that affective prosody may not be as strongly lateralised as propositional language. ${ }^{71-34}$ Seron et $a l^{32}$ reported a significant positive correlation between comprehension of affective prosody and comprehension of propositional language in moderate to severely aphasic patients and proposed that left hemispheric lesions which impair comprehension may also impair decoding of affective prosody. However, alternative explanations are possible. ${ }^{75}$

If it is assumed that affective prosody is a dominant function of the right hemisphere, then the production of speech is likely to entail considerable interhemispheric interaction to ensure that the articulatory-verbal and affective-prosodic elements achieve behavioural unification and temporal coherence. ${ }^{76} 37$ For example, if a speaker wishes to express surprise when uttering a simple sentence, such as "he is clever", then the right hemisphere must be appraised by the left hemisphere of the words that will be articulated and their cadence so that they can be matched with the intended affective-prosodic intonation. On the other hand, it could also be envisioned that the required intonation for affective signalling by the right hemisphere could alter the left hemisphere's plan for articulatory timing. When producing a sarcastic or emphatic statement, ${ }^{38}$ it is often necessary to prolong certain phonetic units to give the correct attitudinal cues. In either case, a left hemispheric lesion could disrupt the higher order linkage of affective prosody and the propositional aspects of speech causing an indirect disruption of affective-prosodic functions.

This possibility was recently explored by Ross et $a l^{7}$ in a series of patients with RBD and LBD. They used an aprosodia battery in which the verbal-articulatory demands are reduced systematically when assessing affective prosody. In patients with $\mathrm{LBD}$, reducing the verbal-articulatory demands caused a highly significant improvement in the ability to comprehend and repeat affective prosody whereas the similar manoeuvre in patients with RBD led to either no improvement or worsening of performance (see figures 1 and 2). More importantly, the affective-prosodic deficits in patients with LBD were not correlated to the presence, severity, or type of aphasic deficits. Based on functional-anatomical assessment, lesions involving the deep white matter adjacent to the corpus callosum, located below the supplementary motor area and cingulate gyrus, best predicted affective-prosodic disturbances compared with the cortical distribution of lesions. By contrast, affective-prosodic deficits in patients with RBD are well correlated with the cortical distribution of the lesion. ${ }^{6}{ }^{39}$ These findings suggest that the predominant mechanism underlying affective-prosodic deficits after LBD is loss of callosal integration of the dominant language functions represented in each hemisphere (LBD/callosal profile), ${ }^{7}$ whereas the predominant mechanism underlying affective-prosodic deficits after RBD is loss of affective-communicative representations, ${ }^{40}{ }^{41}$ and loss of the ability to dominantly modulate affective prosody (RBD/aprosodic profile). ${ }^{7}$

\section{RESEARCH GOAL}

Given the concepts presented above on the contribution of callosal and right and left hemispheric dysfunction to schizophrenia and the complex neurology of affective prosody, an important question to resolve is whether the profile of affective-prosodic disturbances in schizophrenic patients is primarily LBD/ callosal, $\mathrm{RBD} /$ aprosodic, some mixture of the two, or an unexpected variation. By better characterising the profile of affective-prosodic deficits and its relation to behavioural and aphasic symptoms, more valid assumptions concerning the neurological basis of schizophrenia can be formulated.

\section{Methods}

Data were obtained on four subject groups: normal controls, patients with schizophrenia, patients with LBD, and patients with RBD. Subjects were excluded from the study if they had a history of stroke, dementia, closed head injury with residual neurological deficits, severe metabolic conditions caused by renal, liver, cardiac or lung failure, or chronic alcoholism with neurological complications. Subjects were included if they were younger than 65 years to avoid factoring into the statistical analyses recently discovered age related changes in the modulation of affective prosody in elderly subjects. ${ }^{62}$ Patients with RBD and those with LBD were included only if they were strongly right handed, as determined by a score 
Table 1 Subject demographics

\begin{tabular}{llll}
\hline Group & Age & Education & Sex $(M / F)$ \\
\hline${ }^{\star}$ Controls $(\mathrm{n}=19)$ & $45.5(10.8)$ & $14.2(2.1)$ & $7 / 12$ \\
Schizophrenics $(\mathrm{n}=45)$ & $42.5(7.2)$ & $13.8(2.3)$ & $39 / 6$ \\
LBDs (n=10) & $47.4(12.5)$ & $12.5(1.1)$ & $5 / 5$ \\
RBDs (n=9) & $56.2(6.5)$ & $11.6(1.4)$ & $6 / 3$ \\
†Statistical analysis & ANOVA & ANOVA & $\mathrm{K}-\mathrm{W}$ \\
& $F=6.3 ; \mathrm{p}=0.001$ & $F=5.0 ; \mathrm{p}=0.003$ & $\chi^{2}=18.4 ; \mathrm{p}<0.001$ \\
& SNK & SNK & m $\chi^{2}$ \\
& $(\mathbf{S}, \mathbf{C}, \mathbf{L}<\mathbf{R})$ & $(\mathbf{R}<\mathbf{S}, \mathbf{C})$ & $(\mathbf{S} \neq \mathbf{C}, \mathbf{R})$ \\
\hline
\end{tabular}

Values in parentheses are SD.

*No age, education, or sex effects found for controls on the aprosodia battery.

tANOVA=one way analysis of variance, significance level 0.01; SNK=Student-Newman-Kuels (post hoc) test, significance level $0.05 ; \mathrm{K}-\mathrm{W}=$ Kruskal-Wallis one way ANOVA, significance level $0.05 ; \mathrm{m} \chi^{2}=$ multiple $\chi^{2}$ (post hoc) tests, significance level 0.05 .

of +70 on the Edinburgh inventory, ${ }^{43}$ and had documented, unilateral ischaemic infarctions on MRI. Patients with stroke histories or MRI evidence of deep or multiple strokes were excluded. Some severely global aphasic patients were excluded because they were either mute or unable to participate in even low level types of neuropsychological testing. The patients with stroke were tested between 4 and 8 weeks postictus to avoid acute and reversible cognitive deficits due to diaschisis and before the onset of long term recovery. ${ }^{7}$ After complete description of the study was conveyed to the subjects, written informed consent was obtained. For patients with stroke who were aphasic, informed consent was obtained from their next of kin or guardian.

Forty five chronic, medication stabilised schizophrenic patients were accessed into the study. Their clinical diagnoses were based on the patient version of the structured clinical interview for DSM-III-R (SCID). ${ }^{44}$ Thirty eight patients had chronic schizophrenia of the paranoid $(n=24)$ or undifferentiated $(n=14)$ type and seven patients had schizoaffective disorder. Twenty two patients were recruited from the Southeast Human Service Center in Fargo, ND, USA and 23 patients from the VA Hospital in Hartford, CT, USA. Nineteen controls, 10 patients with $\mathrm{LBD}$, and nine with RBD were recruited from the Fargo area. They were selected based on age (<65 years) from our research studies designed to elucidate the neurology of affective prosody. ${ }^{79}$ Subject demographics are presented in table 1 . Although there were group differences for age, sex, and education, none of these factors were found to have an effect on control performance on the aprosodia battery.

\section{DEPENDENT GROUP VARIABLES}

Schizophrenic patients were given the brief psychiatric rating scale (BPRS), ${ }^{45}$ the scale for the assessment of positive symptoms (SAPS), ${ }^{46}$ and the scale for the assessment of negative symptoms (SANS). ${ }^{47}$ All subjects were tested with the aprosodia battery, described below. ${ }^{7}$ Patients with stroke and schizophrenia were tested for propositional language deficits using the western aphasia battery (WAB), ${ }^{48}$ and schizophrenic patients were tested for cognitive decline using the mini mental state examination (MMSE). ${ }^{49}$
The aprosodia battery assesses three levels of affective-prosodic repetition using a prerecorded tape containing the following sets of randomised stimuli: (1) word repetition -12 tokens of the sentence "I am going to the other movies", (2) monosyllabic repetition -12 tokens of the "sentence" "ba ba ba ba ba ba", and (3) asyllabic repetition-12 tokens of the "sentence" "aaaaahhhhh". All sets had two renditions each of neutral, happy, sad, surprised, angry, and disinterested intonations, one with stress early in the sentence and one with stress late in the sentence. The stimulus tape was played in a free auditory field using a Marantz PMD 340 audiocassette recorder. Assessment of spontaneous affective prosody was made by interviewing subjects for 5 to 10 minutes during which time they were encouraged to talk about affectively laden personal life events.

Subjects' verbal responses were taped on a second Marantz PMD 340 recorder using a Shure SM12A microphone mounted on an adjustable boom attached to a headset that was positioned just to the side of the subjects' air stream. Although detailed acoustic measures have been developed to quantify affective prosody, ${ }^{50}{ }^{51}$ these methods are not necessary when analyzing affective prosody in English. English speakers impart affect in their speech predominantly through changes of pitch over time (intonation). ${ }^{135152}$ The most salient acoustic correlate of pitch is fundamental frequency $\left(\mathrm{F}_{0}\right)$, which is equal to the number of vocal fold vibrations per unit of time. ${ }^{52}$ By measuring the change of $F_{0}$ across a series of affective utterances, affective prosody can be quantified sufficiently so as to easily distinguish between normal and abnormal performances. $^{7} 13$

The subjects' voice recordings were analyzed using a PM Pitch Analyzer (Voice Identification Inc) which extracts $\mathrm{F}_{0}$ in $\mathrm{Hz}$ from the speech signal and displays the data on a cathode ray tube. Simultaneously, via a program written using Quick Basic and Macro Assembler languages (Micosoft, Inc), the $F_{0}$ data generated by the pitch analyzer was transferred to a personal computer (Gateway, Inc) at a sampling rate of $10 \mathrm{~ms}$. By using programmable cursors on the pitch analyzer, stray data points caused by microphone artifacts, voice break-ups, and other sampling errors were removed. The computer program then calculated a coefficient of variation (CV) for each utterance. After all the data were completely entered, a mean CV\% was calculated for the 12 sentences $\left(\mathrm{F}_{0}-\mathrm{CV} \%\right)$ comprising each affective set and for 10 seconds of spontaneous speech. $^{753}$

To test affective-prosodic comprehension, four sets of affective-prosodic stimuli were presented. The first three sets used the 12 stimuli described above for the word, monosyllabic, and asyllabic repetition tasks but were presented twice for a total of 24 tokens/set. Subjects identified the affective meanings intoned in the utterances by pointing to one of six choices presented in a vertical array. Each choice was a line drawing of a standardised face 
Table 2 Repeated measures ANOVAs for subject-group pairs on affective repetition

\begin{tabular}{llll}
\hline $\begin{array}{l}\text { Subject-group } \\
\text { pairs }\end{array}$ & $\begin{array}{l}\text { Interactions for group by } \\
\text { task }\end{array}$ & Main effect for group & Main effect for task \\
\hline Con-LBD & $F(2,44)=18.5, \mathrm{p}=0.000$ & $F(1,22)=28.8, \mathrm{p}=0.000$ & $F(2,44)=18.48, \mathrm{p}=0.000$ \\
Con-RBD & $F(2,48)=0.12, \mathrm{p}=0.89$ & $F(1,24)=41.0, \mathrm{p}=0.000$ & $F(2,48)=0.12, \mathrm{p}=0.89$ \\
Con-Schiz & $F(2,92)=0.01, \mathrm{p}=0.98$ & $F(1,46)=45.9, \mathrm{p}=0.000$ & $F(2,92)=0.01, \mathrm{p}=0.98$ \\
RBD-LBD & $F(2,20)=7.53, \mathrm{p}=0.004$ & $F(1,10)=0.89, \mathrm{p}=0.37$ & $F(2,20)=5.62, \mathrm{p}=0.012$ \\
Schiz-LBD & $F(2,64)=9.14, \mathrm{p}=0.000$ & $F(1,32)=0.00, \mathrm{p}=0.97$ & $F(2,64)=9.36, \mathrm{p}=0.000$ \\
Schiz-RBD & $F(2,68)=0.08, \mathrm{p}=0.93$ & $F(1,34)=1.97, \mathrm{p}=0.17$ & $F(2,68)=0.07, \mathrm{p}=0.93$
\end{tabular}

expressing a neutral, happy, sad, indifferent, surprised, or angry emotion accompanied by a written label. ${ }^{54}$

Lastly, a discrimination task was given. Each of the 12 stimuli comprising the word comprehension set was rerecorded after being played through a $70-300 \mathrm{~Hz}$ bandpass filter so as to preserve prosodic information while markedly reducing phonetic information. ${ }^{55}$ A stimulus tape was then made by recording 24 randomised "sentence" pairs from the filtered tape. Twelve sentence pairs had the same affective intonation but different stress patterns and 12 sentence pairs had different intonations but the same stress pattern. The subjects were asked to indicate for each sentence pair if the affect was the same or different. Thus, if subjects made their discriminations based on stress or local prosodic information, a feature modulated to some degree by the left hemisphere, ${ }^{56-58}$ they would do very poorly on this task.

\section{Results}

Statistical analyses were accomplished using SPSS 8.0 for Windows (SPSS Inc). Before the analyses were done all raw data obtained on the aprosodia battery were converted into $\mathrm{Z}$ scores based on the performance of controls (subjects' score-controls' mean score)/controls' SD). ${ }^{53}$ This data transformation removes any variability in performance across the repetition and comprehension tasks of the aprosodia battery attributable to controls but leaves intact the variability attributable to patients so that if statistical interactions are found they may be more easily understood. ${ }^{7}$

APROSODIA BATTERY

Subgroup differences

A preliminary analysis of schizophrenic-type was undertaken to assess for possible differences between patient subgroups (schizoaffective, paranoid, undifferentiated) on the various tasks comprising the aprosodia battery. Using a multivariate analysis of variance (ANOVA) with significance set at 0.01 , no differences were found for subgroup mean performances, which supports the observation by Haskins et $a l^{20}$ that schizoaffective and "schizophrenic" patients are impaired equally on tests of affective prosody. Thus, for the remaining statistical analyses, the schizophrenic patients were treated as a single subject group.

Affective repetition

The $\mathrm{F}_{0}-\mathrm{CV}$ results were analyzed using a repeated measures ANOVA. A significant task by group interaction was found ( $F$ $(6,158)=2.93, \mathrm{p}=0.01)$ with a significant main

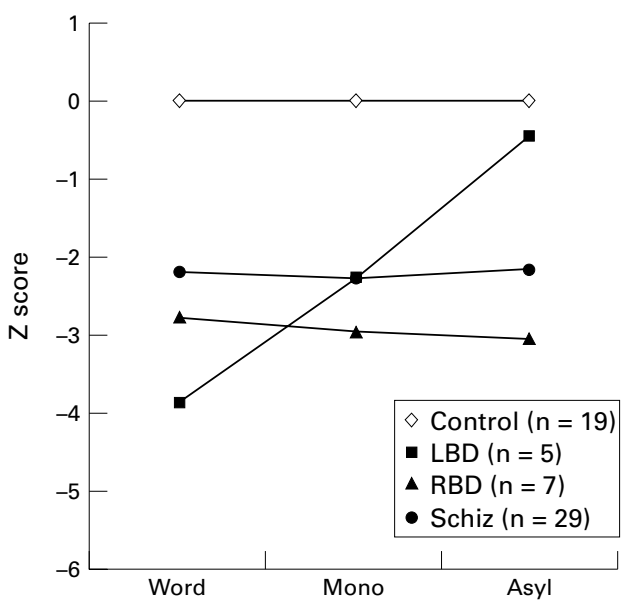

Figure 1 Affective repetition in patients with impaired performance on the aprosodia battery compared with controls. Interaction $p<0.001$; group main effect $p<0.001$; task main effect $p<0.005$. LBD=left brain damage; $R B D=$ right brain damage; Schiz=schizophrenic.

effect for group $(F(3,79)=6.87, \mathrm{p}<0.001)$ and a marginal main effect for task $(F(2,158=3.63$, $\mathrm{p}=0.028$ ). Because our primary research interest was to compare deficit profiles in patients with impaired performance, the data were further reduced by selecting out those patients who had at least one $\mathrm{Z}$ score of less than-1.64 (normal curve proportion of $<0.05$ ) across the tasks. ${ }^{73}$ Using this liberal criterion for impairment, the patient groups had the following number of subjects: schizophrenic 29 of 45 (64.4\%), LBD five of 10 (50\%), and RBD seven of nine $(77.8 \%)$. A repeated measures ANOVA again showed a significant task by group interaction $(F(6,112)=4.28, \mathrm{p}=0.001)$ with significant main effects for group ( $F$ $(3,56)=18.54, \quad \mathrm{p}=0.000)$, and task $(F$ $(2,112)=5.56, \mathrm{p}=0.005)$. As it was essential to preserve the pattern of relations across tasks when performing post hoc statistical analyses to explore the causes for the interaction and main effects, multiple repeated measures ANOVAs for subject group pairs were done (fig 1 , table 2). The task by group interaction was explained by the overall improvement of performance of patients with LBD across tasks compared with controls, patients with RBD and schizophrenia. Most important in answering the research goals of this paper, the only subject group pair that showed neither a significant task by group interaction nor a main effect for group was schizophrenic/RBD, indicating that their patterns of impairment did not differ statistically.

\section{Affective comprehension}

The scores for the four subject groups across affective comprehension tasks and affective discrimination were analyzed using a repeated measures ANOVA. A significant task by group interaction was found $(F \quad(9,237)=4.13$, $\mathrm{p}=0.000)$ with significant main effects for group $(F(3,79)=11.11, \mathrm{p}=0.000)$ and task $(F$ $(3,237)=7.78, \mathrm{p}=0.000)$. As our primary research interest was to compare deficit profiles in patients with impaired performance, the data were further reduced by selecting out 
Table 3 Repeated measures ANOVAs for subject-group pairs on affective comprehension

\begin{tabular}{llll}
\hline $\begin{array}{l}\text { Subject-group } \\
\text { pairs }\end{array}$ & $\begin{array}{l}\text { Interactions for group by } \\
\text { task }\end{array}$ & Main effect for group & Main effect for task \\
\hline Con-LBD & $F(3,72)=4.34, \mathrm{p}=0.007$ & $F(1,24)=39.3, \mathrm{p}=0.000$ & $F(3,72)=4.36, \mathrm{p}=0.007$ \\
Con-RBD & $F(3,78)=10.3, \mathrm{p}=0.000$ & $F(1,26)=62.3, \mathrm{p}=0.000$ & $F(3,78)=10.3, \mathrm{p}=0.000$ \\
Con-Schiz & $F(3,162)=5.47, \mathrm{p}=0.001$ & $F(1,54)=40.7, \mathrm{p}=0.000$ & $F(3,162)=5.5, \mathrm{p}=0.001$ \\
RBD-LBD & $F(3,42)=5.29, \mathrm{p}=0.003$ & $F(1,14)=1.65, \mathrm{p}=0.22$ & $F(3,42)=3.5, \mathrm{p}=0.023$ \\
Schiz-LBD & $F(3,126)=4.24, \mathrm{p}=0.007$ & $F(1,42)=0.74, \mathrm{p}=0.40$ & $F(3,126)=3.5, \mathrm{p}=0.017$ \\
Schiz-RBD & $F(3,132)=0.77, \mathrm{p}=0.51$ & $F(1,44)=0.08, \mathrm{p}=0.78$ & $F(3,132)=13.1, \mathrm{p}=0.000$
\end{tabular}

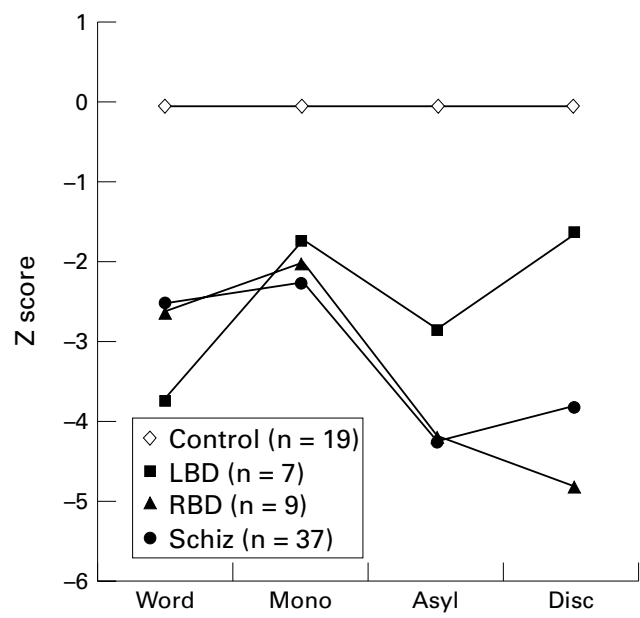

Figure 2 Affective comprehension in patients with impaired performance on the aprosodia battery compared with controls. Interaction $p<0.001$; group main effect $p<0.001$; task main effect $p<0.001$. LBD =left brain damage; $R B D=$ right brain damage; Schiz=schizophrenic.

those patients who had at least one $\mathrm{Z}$ score of less than -1.64 (normal curve proportion of $<0.05$ ) across the tasks. ${ }^{73}$ Using this liberal criterion for impairment resulted in the patient groups having the following number of subjects: schizophrenic 37 of 45 (82.2\%), LBD seven of $10(70 \%)$, and RBD nine of nine $(100 \%)$. A repeated measures ANOVA again showed a significant task by group interaction $(F(9,204)=8.91, \mathrm{p}=0.000)$ with significant main effects for group $(F \quad(3,68)=16.18$, $\mathrm{p}=0.000)$ and task $(F(3,204)=7.17, \mathrm{p}=0.000)$. As above, multiple (post hoc) repeated measure ANOVAs for subject group pairs were done to explore the causes for the interaction and main effects (fig 2, table 3). The interaction was accounted for by overall improvement of patients with LBD and worsening of patients with RBD and schizophrenia across tasks compared with controls and each other. Most important in answering the research goals of this paper, the only subject group pair that showed neither a significant task by group interaction nor a main effect for group was schizophrenic/RBD, indicating that their patterns of impairment did not differ statistically.

\section{Spontaneous affective prosody}

The $\mathrm{F}_{0}-\mathrm{CV}$ results for spontaneous affective prosody were analyzed using a univariate ANOVA. A significant main effect for group ( $F$ $(3,82)=11.49, p=0.000)$ was found. Again, as the primary research interest was in impaired patient performance, the data were further reduced by selecting out those patients who had $\mathrm{Z}$ scores of less than -1.64 (normal curve proportion of <0.05). ${ }^{753}$ This resulted in the patient groups having the following number of subjects: schizophrenic 26 of $45(57.7 \%)$, LBD four of $10(40 \%)$, and RBD six of nine $(66.7 \%)$. A significant main effect for group $(F$ $(3,54)=55.38, p=0.000)$ was found. In examining the results statistically, using the StudentNewman-Kuels (post hoc) test with significance set at 0.05 , the main effect was accounted for by all three patient groups performing differently from controls but not from each other. The group $\mathrm{Z}$ score means were controls $=0.0(1.0)$, schizophrenic $=-2.89$ (0.78), $\mathrm{LBD}=-2.61(0.27)$, and $\mathrm{RBD}=-2.82$ (0.62).

DISTRIBUTION OF APROSODIC DEFICITS IN SCHIZOPHRENIC PATIENTS

Schizophrenic patients were classified as having an aprosodic deficit if their $\mathrm{Z}$ score performance was $<-2.0$ on spontaneous affective prosody (normal curve proportion of $<0.0228),{ }^{53}$ or if their average $\mathrm{Z}$ score on affective repetition (three levels) or affective comprehension (four levels) was $<-2.0$. Using this statistically conservative method for classifying patients, 38 of the 45 schizophrenic patients $(84.4 \%)$ had some type of aprosodic deficit. Loss of comprehension was the most common abnormality found in 26 patients $(57.8 \%)$ suggesting, at minimum, posterior sylvian cortical dysfunction. ${ }^{49}{ }^{59-61}$ Twenty three $(51.1 \%$ ) had deficits involving spontaneous affective prosody suggesting, at minimum, anteriorsuperior sylvian dysfunction, ${ }^{346}{ }^{39}$ whereas 15 (39.5\%) had deficits involving repetition suggesting, at minimum, perisylvian dysfunction. ${ }^{4639}$

WESTERN APHASIA BATTERY

The results on the WAB varied for the three patient groups. None of nine patients with RBD had an abnormal aphasia quotient (AQ), as defined by a score less than $93.8 .^{48}$ Seven of 45 schizophrenic patients $(15.5 \%)$ had mildly abnormal AQs (mean=86.3 (6.2)) and five of 10 patients with LBD (50\%) had abnormal AQs (mean=63.6 (27.8)). As the AQ showed marked inhomogeneity of variance $(p<0.001)$ due to the excessive SD found in the LBD compared with the RBD and schizophrenic groups, the data were reduced by classifying patients as having either normal or abnormal AQs. Using a $2 \times 3$ contingency table, a $\chi^{2}$ of $8.79(\mathrm{df}=2, \mathrm{p}=0.012)$ was found. Based on multiple $(2 \times 2)$ Fisher's exact tests, the LBD distribution was different from both the RBD and schizophrenic distributions (two tailed $\mathrm{p}=0.03$ ) but the RBD distribution was not different from the schizophrenic distribution (two tailed $\mathrm{p}=0.58$ ).

RELATION OF PERFORMANCE ON THE APROSODIA BATTERY TO SCHIZOPHRENIC SYMPTOMS

In the schizophrenic group, clinical symptoms were evaluated using the 18 item BPRS, 24 item SANS, and 35 item SAPS. To assess the reliability and validity of the scores, a factor analysis was done to see if the resulting symptom clusters in our patient population were 
Table 4 Rotated factor analysis of schizophrenic symptoms and aprosodia battery results

\begin{tabular}{|c|c|c|c|c|}
\hline Factor & Variance & $\Sigma$ variance & Principal components & $\begin{array}{l}\text { Loading } \\
\text { scores }\end{array}$ \\
\hline 1 & $17.9 \%$ & $17.9 \%$ & $\begin{array}{l}\text { PCA } \text { : hallucinations/paranoid delusions } \\
\text { BPRS: mean } \\
\text { Gur: suspicion/hostility } \\
\text { Gur*: schneiderian hallucinations/delusions } \\
\text { SAPS: delusions } \\
\text { SAPS: hallucinations }\end{array}$ & $\begin{array}{l}0.971 \\
0.888 \\
0.853 \\
0.825 \\
0.814 \\
0.729\end{array}$ \\
\hline 2 & $14.5 \%$ & $32.4 \%$ & $\begin{array}{l}\text { PCA: affective blunting/flattening-alogia } \\
\text { SANS: alogia } \\
\text { SANS: affective blunting/flattening } \\
\text { Gur: negative } \\
\text { SANS: attention }\end{array}$ & $\begin{array}{l}0.964 \\
0.849 \\
0.802 \\
0.757 \\
0.578\end{array}$ \\
\hline 3 & $11.8 \%$ & $44.2 \%$ & $\begin{array}{l}\text { ApB }{ }^{\star}: \text { word comprehension } \\
\text { ApB: monosyllabic comprehension } \\
\text { ApB: asyllabic comprehension } \\
\text { ApB: affective discrimination }\end{array}$ & $\begin{array}{l}0.844 \\
0.853 \\
0.830 \\
0.779\end{array}$ \\
\hline 4 & $10.6 \%$ & $54.8 \%$ & $\begin{array}{l}\text { PCA: formal thought disorder } \\
\text { SAPS: formal thought disorder } \\
\text { Gur: disorganisation }\end{array}$ & $\begin{array}{l}0.973 \\
0.947 \\
0.727\end{array}$ \\
\hline 5 & $10.2 \%$ & $65.0 \%$ & $\begin{array}{l}\text { PCA: avolition/apathy-anhedonia/asociality } \\
\text { SANS: avolition/apathy } \\
\text { SANS: anhedonia/asociality } \\
\text { ApB: spontaneous affective prosody }\end{array}$ & $\begin{array}{l}0.933 \\
0.741 \\
0.663 \\
-0.564\end{array}$ \\
\hline 6 & $9.8 \%$ & $74.8 \%$ & $\begin{array}{l}\text { ApB: monosyllabic repetition } \\
\text { ApB: asyllabic repetition } \\
\text { ApB: word repetition }\end{array}$ & $\begin{array}{l}0.866 \\
0.860 \\
0.825\end{array}$ \\
\hline 7 & $7.2 \%$ & $82.0 \%$ & $\begin{array}{l}\text { PCA: bizarre behaviours-mannerisms } \\
\text { SAPS: bizarre behaviours }\end{array}$ & $\begin{array}{l}0.931 \\
0.722\end{array}$ \\
\hline
\end{tabular}

${ }^{\star} \mathrm{PCA}=$ factors found on initial principal component analysis using the items on the BPRS, SANS, and SAPS; Gur=Gur et a $l^{64}$ categories; $\mathrm{ApB}=$ aprosodia battery.

consistent with previously reported research. ${ }^{62}$ The 77 items were subjected to a principal components factor analysis followed by a varimax rotation with Kaiser normalisation. Five factors, accounting for $54 \%$ of the variance, seemed to adequately describe the data based on visual inspection of the scree plot and the rotational sums of squared loadings. The five derived symptom categories, using the distribution of principal components having an absolute value $\geqslant 0.5$, are displayed in table 4 next to the label "PCA." All the factors had positive loading scores. Our results compare favourably with the symptom clusters derived by Kawasaki et $a l^{62}$ in 70 acute and chronic schizophrenic patients and by Peralta et $a l^{63}$ in 115 hospitalised schizophrenic patients. A principal component analysis with varimax rotation was used in both patients.

In addition to the above five factor scores, total scores for each patient were calculated for the five subtests on the SANS and SAPS by adding together the results for each question making up a subtest. A mean score was calculated for the BPRS. Finally, specific items from the SANS, SAPS, and BPRS were weighted and averaged based on the technique of Gur et $a l^{64}$ who used a "rational-statistical" approach to develop their four schizophrenic symptom categories. Using the above 19 derived symptom categories plus the eight measures from the aprosodia battery and the scores on the MMSE and WAB AQ, a principal components factor analysis was done followed by a varimax rotation with Kaiser normalisation. Seven factors, accounting for $82 \%$ of the variance, seemed to adequately describe the data based on visual inspection of the scree plot and the rotational sums of squared loadings. Table 4 displays the loading of various items with absolute values of $\geqslant 0.5$ onto the seven factors. The
19 symptom categories seem to cluster appropriately onto factors $1,2,4,5$, and 7 . An unexpected finding was that the tasks measuring affective comprehension (factor 3) and affective repetition (factor 6 ) did not cluster with any of the symptom categories. As might be predicted, spontaneous affective prosody had a negative loading score on factor 5 . Interestingly, neither the MMSE nor the WAB AQ loaded onto any of the seven factors.

\section{Discussion}

The results indicate that affective-prosodic impairments in schizophrenia are consistent with a right hemispheric type of deficit (RBD/ aprosodic profile) rather than loss of callosal integration (LBD/callosal profile) or an unexpected profile. This finding reinforces the idea that schizophrenia is not simply a left hemispheric disease process but rather affects cognitive systems in both hemispheres. ${ }^{16-19} 2627$ Overall, $84.4 \%$ of the schizophrenic patients had an aprosodia, whereas only $15.5 \%$ of the patients had abnormal AQ scores on the western aphasia battery suggesting mild types of aphasic deficits. This indicates that, at least for language and communication, the schizophrenic process is asymmetric as it affects systems represented predominantly in the right rather than the left hemisphere. If schizophrenic patients cannot appropriately modulate affective prosody, and also have difficulty processing facial affect, ${ }^{65-67}$ it is likely that their ability to interact in social situations will be disrupted leading to impoverished interpersonal relationships and social isolation. ${ }^{68}$ Studies relating these phenomena to affect recognition and traditional clusters of schizophrenic symptoms have linked impoverished social skills to overall severity of clinical symptoms rather than specific symptom categories. Of interest in our study, affective comprehension and repetition did not load with any of the derived schizophrenic symptom clusters on factor analysis, which suggests that these deficits may well represent cardinal features of schizophrenia, ${ }^{62}{ }^{63}$ which might be part of, or at least a major contributor to, a separate core defect regulating social interactions. ${ }^{68}$ If this is so, metabolic correlates indicating hypometabolism of the right posterior sylvian cortices in schizophrenic patients might be expected as this area has been shown in patients with brain damage to be important for comprehension of affective prosody. ${ }^{49} 59-61$

Some investigators have incidentally noted hypometabolism involving the right posterior sylvian region in schizophrenic patients when studying the phenomenon of hypofrontality by PET or SPECT. ${ }^{69}{ }^{70}$ More recent studies have also found relative hypometabolism of the left posteriorsylvian region that seems related to the presence of positive symptoms, in particular hallucinations. ${ }^{62} 7172$ Thus, as with hypofrontality, the results are mixed for temporal lobe involvement across groups of schizophrenic patients which some authors have suggested probably reflects symptom heterogeniety. ${ }^{62}{ }^{63}{ }^{69}$ A recent PET study by O'Leary et $a l,{ }^{73}$ however, is of interest. They assessed 10 
unmedicated schizophrenic patients using various binaural and dichotic activation paradigms designed to probe hemispheric auditory attention and the ability to inhibit competing auditory stimuli. ${ }^{74}$ The investigators found that the schizophrenic patients did not appropriately activate their right superotemporal gyrus compared with controls and that patient performance was statistically related to the metabolic findings. In keeping with our finding that about $58 \%$ of our schizophrenic patients had problems with affective comprehension, a putative function involving the right posterior sylvian area, ${ }^{49}{ }^{59-61} 50 \%$ of the schizophrenic patients studied by O'Leary et $a l^{73}$ were categorised as "poor performers" on the auditory tasks used to probe the right superotemporal gyrus.

In reviewing previous research documenting aprosodic deficits in schizophrenia, various publications have reported problems with production, ${ }^{13-15} 17$ or production and comprehension, ${ }^{18} 19$ and, in some cases, repetition. ${ }^{162122}$ All used tasks in which affectiveprosodic stimuli were presented using articulated sentences or phrases as carriers of affect with the assumption that the observed deficits reflected right hemispheric dysfunction. The current study, which utilised an aprosodia battery designed to distinguish affective-prosodic deficits due to RBD versus $\mathrm{LBD},{ }^{7}$ robustly supports the assumption made by previous researchers that schizophrenic impairments in affective prosody are the result of right hemispheric dysfunction.

The primary weakness of our study is that all the schizophrenic patients were on neuroleptic drugs at the time of testing. Some investigators, however, have reported that affective flattening and affective comprehension deficits are not correlated with neuroleptic treatment. ${ }^{1315182075}$ In a previous quantitative study of affective prosody, Ross et $a l^{76}$ assessed 20 schizophrenic outpatients who were in hospital on a research ward at the Dallas VA Medical Center. Testing was undertaken when the patients were off all psychotropic medications for at least 2 weeks. Fifty five per cent of the patients demonstrated deficits in affectiveprosodic comprehension, $40 \%$ had problems with affective repetition, and $35 \%$ showed flattening of spontaneous affective prosody. This distribution is similar to the findings presented here and supports previous publications suggesting that neuroleptic use is not an important contributor to affective-prosodic deficits in schizophrenia. ${ }^{13152075}$

This work was supported by a grant from the EJLB Foundation, Montreal, Canada, to EDR and RB and, in part, by a grant from the VA Merit Review Board, Washington, DC, to EDR. We are indebted to Andrew McLean and his staff at the Southeast Human Service Center in Fargo, ND, and Laurence Schwitzer, Human Service Center in Fargo, ND, and Laurence Schwitzer,
and his staff at the VA Medical Center in Newington, CT, for allowing us access to their patients.

1 Abrams R, Taylor MA. A rating scale for emotional blunting Am f Psychiatry 1978; 135:225-9.

2 Andreasen NC. Affective flattening and the criteria for schizophrenia. Am f Psychiatry 1979;136:944-7.

3 Ross ED, Mesulam M-M. Dominant language functions of the right hemisphere?: prosody and emotional gesturing. Arch Neurol 1979;36:144-8.
4 Ross ED. The aprosodias: functional-anatomic organization of the affective components of language in the right hemiof the affective components of lang
sphere. Arch Neurol 1981;38:561-9.

5 Buck R, Duffy R. Non-verbal communication of affect in brain-damaged patients. Cortex 1980;16:351-62.

6 Ross ED. Affective prosody and the aprosodias. In: Mesulam MM, ed. Principles of behavioral and cognitive neurology. New York: Oxford University Press, 2000:316-31.

7 Ross ED, Stark RD, Yenkosky JP. Lateralization of affective prosody in brain and the callosal integration of hemispheric language functions. Brain Lang 1997;56:27-54.

8 Ross ED, Rush AJ. Diagnosis and neuroanatomical correlates of depression in brain-damaged patients: implications for a neurology of depression. Arch Gen Psychiatry 1981;38:1344-54.

9 Ross ED, Stewart R. Pathological display of affect in patients with depression and right focal brain damage: an patients with depression and right focal brain damage: an

10 Schneider F, Gur RC, Gur RE, et al. Emotional processing in schizophrenia: neurobehavioral probes in relation to in schizophrenia: neurobehavioral probes in

11 Sweet LH, Primeau M, Fichtner CG, et al. Dissociation of affect recognition and mood state from blunting in patients with schizophrenia. Psychiatry Res 1998;81:301-8.

2 Flack WF, Laird JD, Cavallaro LA. Emotional expression and feeling in schizophrenia: effects of specific expressive behaviors on emotional experiences. $f$ Clin Psychol 1999;55:1-20

13 Andreasen NC, Alpert M, Martz MJ. Acoustic analysis: an objective measure of affective flattening. Arch Gen Psychiatry 1981;38:281-5

14 Leff J, Abberton E. Voice pitch measurements in schizophrenia and depression. Psychol Med 1981;11:849-52.

15 Levin S, Hall JA, Knight RA, et al. Verbal and non-verbal expression of affect in speech of schizophrenic and depressed patients. F Abnorm Psychol 1985;94:487-97.

16 Fricchione G, Sedler MJ, Shukla S. Aprosodia in eight schizophrenic patients. Am f Psychiatry 1986;143:1457-9.

17 Alpert M, Rosen A, Welkowitz J, et al. Vocal acoustic correlates of flat affect in schizophrenia. $\mathrm{Br} \quad \mathcal{F}$ Psychiatry 1989;154(suppl 4):51-6.

18 Borod JC, Alpert M, Brozgold A, et al. A preliminary comparison of flat affect schizophrenics and brain-damaged patients on measures of affective processing. $\mathcal{f}$ Commun Disord 1989;22:93-104.

19 Murphy D, Cutting J. Prosodic comprehension and expression in schizophrenia. 7 Neurol Neurosurg Psychiatry 1990;53:727-30.

20 Haskins B, Shutty MS, Kellogg E. Affect processing in chronically psychotic patients: development of a reliable assessment tool. Schizophr Res 1995;15:291-7.

21 Leentjens AFG, Wielaert SM, van Harskamp F, et al. Disturbances of affective prosody in patients with schizophrenia; a cross sectional study. $\mathcal{f}$ Neurol Neurosurg Psychiatry 1998;64:375-8.

22 Cutting J, Murphy D. Preference for denotative as opposed to connotative meanings in schizophrenics. Brain Lang 1990;39:459-68

23 Di Simoni GG, Darley FL, Aronson AE. Patterns of dysfunction in schizophrenic patients on an aphasia test battery. Fournal of Speech and Hearing Disorders 1977;42: 498-513.

24 Cutting J. The right cerebral hemisphere and psychiatric disorders. New York: Oxford University Press, 1990:30312.

25 Sims A, ed. Speech and language disorders in psychiatry. Proceedings of the 5th Leeds Psycopathology Symposium. Part II. Schizophrenic disturbances of speech and language. II. Schizophrenic disturbances of speech

26 Taylor MA, Abrams R. Cognitive impairment pattern in schizophrenia and affective disorder. $\mathcal{F}$ Neuropsychiatry Neuropsychol Behav Neurol 1987;50:895-9.

27 Cutting J. The role of right hemisphere dysfunction in psychiatric disorders. Br F Psychiat 1992;160:583-8.

28 Coger RW, Serafetinides EA. Schizophrenia, corpus callosum, and interhemispheric communication: a review. Psychiatry Res 1990;34:163-84.

29 Merriam AE, Gardner EB. Corpus callosum function in schizophrenia: a neuropsychological assessment of interhemispheric information processing. Neuropsychologia 1987;25:185-93.

30 Raine A, Andrews H, Sheard C, et al. Interhemispheric transfer in schizophrenics, depressives, and normals with schizoid tendencies. F Abnorm Psychol 1989;98:35-41.

31 Schlanger BB, Schlanger P, Gerstmann LJ. The perception Schlanger BB, Schlanger P, Gerstmann LJ. The perception
of emotionally toned sentences by right hemispheredamaged and aphasic subjects. Brain Lang 1976;3:396403.

32 Seron X, van der Kaa MA, van der Linden M, et al. Decoding paralinguistic signals: effect of semantic and prosodic cues on aphasic comprehension. F Commun Disord 1982;15:223-31

33 De Bleser R, Poeck K. Analysis of prosody in the spontaneous speech of patients with CV-recurring utterances. Cortex 1985;21:405-16.

34 Cancelliere AEB, Kertesz A. Lesion localization in acquired deficits of emotional expression and comprehension. Brain Cogn 1990;13:133-47.

35 Ross ED. Prosody and brain lateralization: fact vs fancy or is it all just semantics? Arch Neurol 1988;45:338-9.

36 Ross ED, Harney JH, de Lacoste C, et al. How the brain integrates affective and propositional language into a unified brain function. Hypotheses based on clinicopathological correlations. Arch Neurol 1981;38:745-8. 
37 Speedie LJ, Coslett B, Heilman K. Repetition of affective prosody in mixed transcortical aphasia. Arch Neurol prosody in mixed

38 Bolinger D. Language: the loaded weapon. London: Longman Group, 1980

39 Ross ED, Orbelo DM, Burgard M, et al. Functionalanatomic correlates of aprosodic deficits in patients with right brain damage. Neurology 1998;50(suppl 4):A363.

40 Blonder LX, Bowers D, Heilman KM. The role of the righ hemisphere in emotional communication. Brain 1991;114 1115-27.

41 Bowers D, Bauer RM, Heilman KM. The non-verbal affect lexicon: theoretical perspectives from neuropsychological studies of affect perception. Neuropsychology 1993;7:43344.

42 Ross ED, Orbelo DM, Testa JA, et al. Age-related changes in processing affective prosody. Neurology 2000;54(suppl 3):A418-19.

43 Oldfield RC. The assessment and analysis of handedness: the Edinburgh inventory. Neuropsychologia 1971;9:97-113.

44 Spitzer RL, Williams JBW, Gibbon M, et al. Instruction manual for the structured clinical interview for DSM-III-R $(S C I D)$. New York: New York Psychiatric Institute, 1988

45 Overall JE, Gorman DR. The brief psychiatric rating scale. Psychol Rep 1962;10:799-812.

46 Andreasen NC. The scale for the assessment of positive symptoms (SAPS). Iowa City: University of Iowa, 1984.

47 Andreasen NC. The scale for the assessment of negative symptoms (SANS). Iowa City: University of Iowa, 1983.

48 Kertesz A. Western aphasia battery. New York: Grune and Stratton, 1982

49 Folstein MF, Folstein SE, McHugh P. Mini-mental state: a practical method for grading the cognitive state of patients for the clinician. F Psychiatry Res 1975;12:189-98.

50 Ross ED, Edmondson JA, Seibert GB. The effect of affect on various acoustic measures of prosody in tone and nontone languages: a comparison based on computer analysis. 7 Phonetics 1986;14:283-302.

51 Ross ED, Edmondson JA, Seibert GB, et al. Acoustic analysis of affective prosody during right-sided Wada test: a sis of affective prosody during right-sided Wada test: a within-subjects verification of the right
language. Brain Lang 1987;33,128-45.

52 Lieberman P. Speech physiology and acoustical phonetics. New York: MacMillan, 1977.

53 Zar J. Biostatistical analysis. Englewood Cliffs: Prentice Hall, 1984

54 Walston YW. A design study: testing the perception of emotions in brain damaged patients with contour drawings of facial expressions [MA Thesis]. Dallas, Texas: Department of Biomedical Communication, University of Texas Southwestern Medical Center, 1982

55 Lenhardt ML. Factors in affective discrimination of speech Neurology 1978;28:309-10.

56 Heilman KM, Bowers D, Speedie L, et al. Comprehension of affective and non-affective prosody. Neurology 1984;34 917-21.

57 Weintraub S, Mesulam M-M, Kramer L. Disturbances in prosody. Arch Neurol 1981;38:742-4.

58 Emmorey $\mathrm{K}$. The neurologic substrates for the prosodic aspects of speech. Brain Lang 1987;30:305-20.
59 Heilman KM, Scholes R, Watson RT. Auditory affective gnosia: disturbed comprehension of affective speech. $\mathcal{F}$ agnosia: disturbed comprehension of affe

60 Darby DG. Sensory aprosodia: a clinical clue to lesions of the inferior division of the right middle cerebral artery? Neurology 1993;34:567-72

61 Starkstein SE, Federoff JP, Price TR, et al. Neuropsychological and neuroradiologic correlates of emotional prosody comprehension. Neurology 1994;44:515-22.

62 Kawasaki Y, Maeda Y, Sakai N, et al. Regional cerebral blood flow in patients with schizophrenia: relevance to symptom structures. Psychiatry Res 1996;67:49-58.

63 Peralta V, de Leon J, Cuesta MJ. Are there more than two syndromes in schizophrenia? A critique of the positivenyndromes in schizophrenia? A critique of the posive dichotomy. Br f Psychiatry 1992;161:335-43.

64 Gur RE, Mozley PD, Shtasel DL, et al. Clinical subtypes of schizophrenia: differences in brain and CSF volume. Am $\mathcal{F}$ Psychiatry 1994;151:343-50.

65 Borod JC, Martin CC, Alpert M, et al. Perception of facial motion in schizophrenic and right brain-damaged patients. F Nerv Ment Dis 1993;181:494-502.

66 Feinberg TE, Rifkin A, Schaffer C, et al. Facial discrimination and emotional recognition on schizophrenia and affective disorders. Arch Gen Psychiatry 1986;43:276-9.

67 Schneider F, Gur RC, Gur RE, et al. Emotional processing in schizophrenia: neurobehavioral probes in relation to in schizophrenia: neurobehavioral probes in

68 Pool JH, Tobias FC, Vinogradov S. The functional relevance of affect recognition errors in schizophrenia. F Int Neuropsychol Soc 2000;6:649-58.

69 Kishimoto H, Kuwahara H, Ohno S, et al. Three subtypes of chronic schizophrenia identified using ${ }^{11} \mathrm{C}$-glucose positron emission tomography. Psychiatry Res 1987;21:285-92.

70 Paulman RG, Devous MD, Gregory RR, et al. Hypofrontality and cognitive impairment in schizophrenia: dynamic single-photon tomography and neuropsychological assessment of schizophrenic brain function. Biol Psychiatry 1990; 27:377-99.

71 Cleghorn JM, Garnett ES, Nahmias C, et al. Regional brain metabolism during auditory hallucinations in chronic metabolism during auditory hallucinations in

72 Sabri O, Erkwoh R, Schreckenberger M, et al. Correlation of positive symptoms exclusively to hyperperfusion of hypoprfusion of cerebral cortex in never-treated schizophrenics. Lancet 1997:349:1735-9.

73 O'Leary DS, Andreasen NC, Hurtig RR, et al. Auditory attentional deficits in patients with schizophrenia. Arch Gen Psychiatry 1996;53:633-41.

74 O'Leary DS, Andreasen NC, Hurtig RR, et al. A positron emission tomography study of binaurally and dichotically presented stimuli: effects of level of language and directed attention. Brain Lang 1996;53:20-39.

75 Borod JC, Welkowitz J, Alpert M, et al. Parameters of emotional processing in neuropsychiatric disorders: conceptual issues and a battery of tests. F Commun Disord 1990;23: 247-71.

76 Ross ED, Morgan-Fisher A, Paulman RG, et al. Affectiveprosodic deficits in schizophrenia. Biol Psychiatry 1989; 25(suppl):105-6a. 